\title{
O estetoscópio e os sons pulmonares: uma revisão da literatura
}

\author{
The stethoscope and the pulmonary sounds: \\ a literature review
}

\author{
Vitor Oliveira Carvalho', Germano Emílio Conceição Souza²
}

\begin{abstract}
Carvalho VO, Souza GEC. O estetoscópio e os sons pulmonares: uma revisão da literatura. Rev Med (São Paulo). 2007 out.-dez.;86(4):224-31.

RESUMO: A ausculta torácica é uma técnica diagnóstica muito antiga, amplamente usada na atualidade pelo seu baixo custo, grande praticidade e sensibilidade. Os diversos sons audíveis pelo estetoscópio sugerem condições pulmonares de grande importância para o tratamento dos enfermos. Estes sons são resultados das vibrações pulmonares e das respectivas vias aéreas transmitidas à parede torácica. Eles podem ser divididos primeiramente em: bronquiais (traqueobronquiais) ou vesiculares, não existindo padronização na sua descrição. Esta revisão tem como objetivo mostrar o que existe sobre os sons pulmonares e seus significados.
\end{abstract}

DESCRITORES: Sons respiratórios. Estetoscópios. Auscultação. Literatura de revisão.

\section{Considerações históricas}

A ausculta torácica é uma técnica diagnóstica muito antiga ${ }^{1}$. Hipócrates já recomendava colocar o ouvido em contato com a superfície do tórax de seus pacientes para a percepção dos sons "provenientes do meio interno"1,2.

René Théophile Hyacinth Laennec, médico francês (1781-1826), observou duas crianças que brincavam de enviar sinal uma a outra através de uma madeira longa e sólida, raspando com um pino em uma extremidade e ouvindo com o ouvido pressionado na outra ${ }^{1,2}$. Em 1816, exercendo suas atividades médicas em um hospital de Paris, deparou-se com uma paciente obesa que deveria examinar, mas os costumes da época não permitiam que ele colocasse seu ouvido no tórax da mesma sem violar as normas

\footnotetext{
${ }^{1}$ Fisioterapeuta, Doutorando em Cardiologia pela Faculdade de Medicina da USP.

${ }^{2}$ Médico assistente do InCor HCFMUSP. Doutorando em Cardiologia pela Faculdade de Medicina da USP.

Endereço para correspondência: Vitor Oliveira Carvalho. Rua Teodoro Sampaio, 363 ap. 304. São Paulo - SP. e-mail: vitor.carvalho@usp.br
} 
sociais e culturais ${ }^{3}$. Laennec lembrou das crianças que brincavam e teve a idéia de enrolar um cone de papel e aplicar uma extremidade sobre o coração e a outra a sua orelha e descobriu que os sons tornavam-se mais altos do que a ausculta direta ${ }^{1}$. Inicialmente este aparelho era de papel, tornando-se posteriormente de madeira ${ }^{1}$. O médico francês havia inventado um aparelho capaz de ouvir os sons internos, o estetoscópio ${ }^{1,2,3}$. A palavra estetoscópio vem do grego stethos $=$ peito e skopein $=$ exploração ${ }^{1,3}$.

O estetoscópio evoluiu através dos tempos quando em 1894, Bianchi inventou o "diafragma rígido", em 1925 Bowles e Sprague combinaram a campânula com o diafragma rígido e em 1955-46 Rappaport, Sprague e Groom aperfeiçoaram nos moldes atuais ${ }^{1}$. O uso deste aparelho oferece um dos mais importantes e simples métodos diagnósticos e de informações sobre a estrutura e a função do pulmão por uma forma não invasiva ${ }^{4}$. Apesar do custo elevado dos modernos aparelhos, os mesmos são simples condutores de sons entre as superfícies corpóreas e os ouvidos, podendo amplificar ou atenuar seletivamente em um certo espectro de interesse clínico ${ }^{5}$. As amplificações tendem a ocorrer em freqüências abaixo de $112 \mathrm{~Hz}$ e a atenuação em freqüências maiores ${ }^{5}$. Esta característica é inerente ao projeto do aparelho que, freqüentemente, coloca a conveniência e a utilidade clínica antes de uma grande finalidade acústica ${ }^{5}$.

O estetoscópio clássico é composto de cinco partes: (1) olivas; (2) binaurais; (3) tubo; (4) campânula; (5) diafragma (Figura 1).

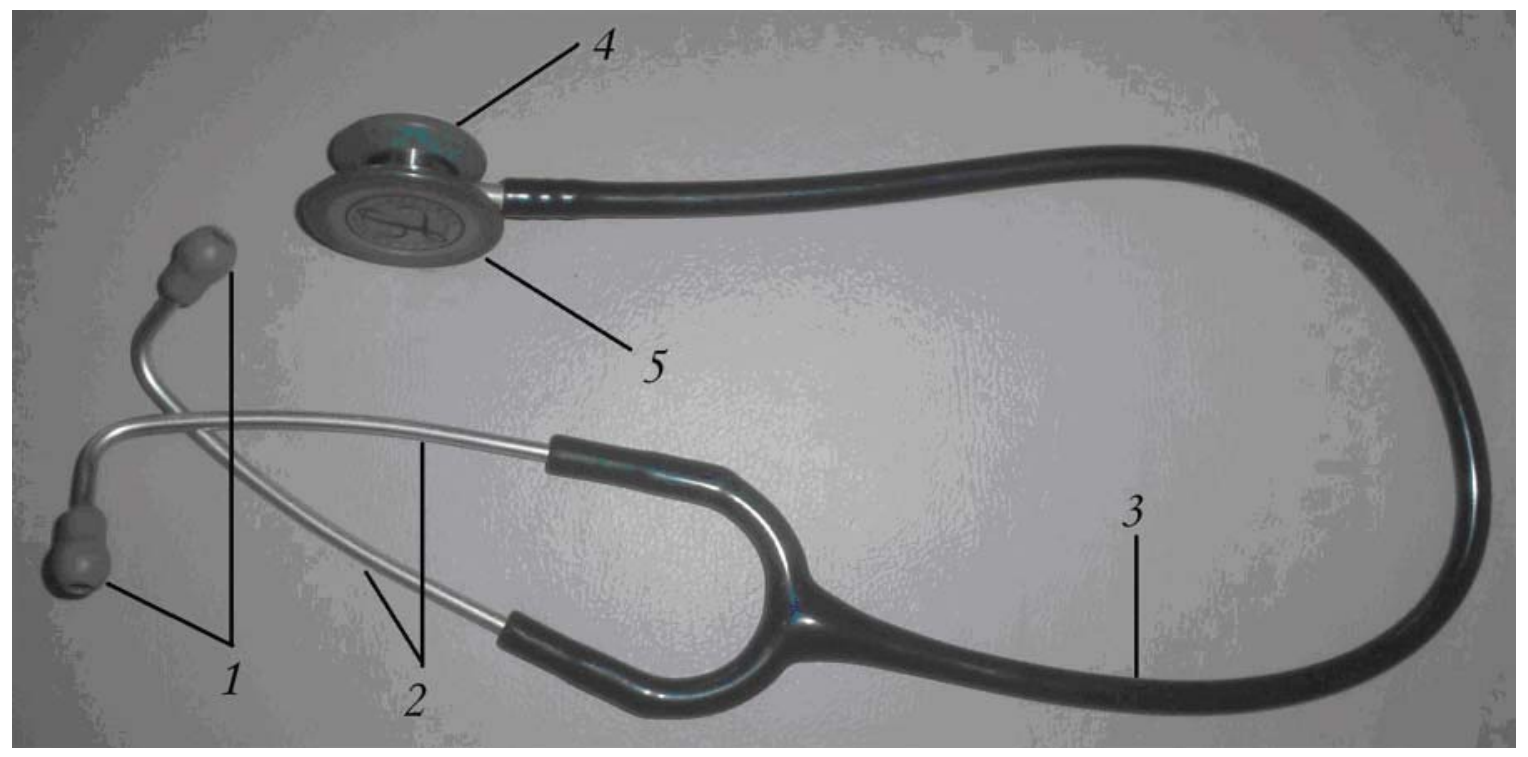

Figura 1. Estetoscópio clássico

\section{Sons pulmonares normais}

A história do estudo dos sons pulmonares passa também pela história do estetoscópio. Laennec não somente inventou o estetoscópio, como comparou os sons com achados após a morte'. Em 1819 publicou o inédito tratado de ausculta "L'auscultation mediate", dando início ao estudo dos sons pulmonares ${ }^{1}$.

Os sons pulmonares são resultados das vibrações pulmonares e das respectivas vias aéreas transmitidas à parede torácica². Esta caixa torácica, embora relativamente fina comparada com a extensão do parênquima pulmonar, é significativamente mais maciça, dura e heterogênea por conter músculos e ossos de forma que favorece uma pior transmissão dos sons ${ }^{5}$. Os mesmos vêem sendo estudados com muitas dificuldades ao longo dos anos devido às amplas faixas de freqüências geradas e por dependerem das taxas de fluxos de ar, fases inspiratórias ou expiratórias, locais dos pulmões onde estão sendo obtidas as informações, graus de controles voluntários que os indivíduos podem exercer nas respirações e pelas interferências com os sons cardíacos ${ }^{2,5}$. Existem indícios, também, de que o volume pulmonar pode interferir na geração dos sons normais ${ }^{5}$. Outra dificuldade é a falta de padronização nos estudos, não permitindo a comparação entre os mesmos ${ }^{2}$, apesar da maioria dos trabalhos realizarem mensurações por meio de eletrodos que funcionam como microfones ${ }^{5}$. Os estudos das propriedades acústicas do sistema respiratório são de fundamental importância para avanços no meio diagnóstico e de triagem ${ }^{5}$. No 
presente momento, não existe uma padronização internacional destes sons ${ }^{4}$.

Os sons pulmonares normais podem ser divididos em sons bronquiais (traqueobronquiais) ou vesiculares ${ }^{2}$.

Os sons bronquiais podem ser auscultados em uma ventilação normal na região da via aérea superior, entre a cavidade nasal e o brônquio principal ${ }^{2}$. Estes possuem uma característica "tubular", típica de ar passando por vias de maiores calibres, $4 \mathrm{~mm}$ ou mais de diâmetro². Quando estes sons são ouvidos fora das áreas traqueobronquiais, traduz infiltrações no parênquima pulmonar porque os tecidos consolidados funcionam como melhores condutores de som (devido sua maior densidade) do que os tecidos normais ${ }^{2}$.

Estudos revisados por Dalmay et al. ${ }^{2}$, mostraram uma variação de 60 a $900 \mathrm{~Hz}$ nos sons bronquiais. Este amplo espectro de som encontrado reflete a falta de padronização dos trabalhos e a grande dependência com a taxa de fluxo de ar e das dimensões da traquéia ${ }^{2,4,5}$. A dimensão da mesma está diretamente ligada à altura do corpo ${ }^{4}$, de forma que uma criança possui sons mais altos do que os adultos $^{5}$, assim como as freqüências $(\mathrm{Hz})$ a um fluxo pré-determinado ${ }^{2}$. Em outro estudo revisado pelo mesmo autor usando indivíduos normais e taxas de fluxos de ar em 0.4, 0.6 e $0.9 \mathrm{Ls}^{-1}$, observou-se que: 1) o espectro foi virtualmente idêntico na inspiração e na expiração e a forma das ondas eram bastante similares acima de $1 \mathrm{KHz}$ em todos os sujeitos; 2) a amplitude do som aumentou em proporção ao aumento da taxa de fluxo em uma freqüência entre 100 e aproximadamente $800 \mathrm{~Hz}$; 3) os sons traqueobrônquicos foram detectados a partir de $100 \mathrm{~Hz}$ e suas energias concentradas entre 100 e $1.200 \mathrm{~Hz}$; e 5) a amplitude do som saiu da linha de base nos níveis de 1.200 e $1.800 \mathrm{~Hz}$, dependendo do indivíduo medido.

Os sons vesiculares foram atribuídos por alguns médicos do século 19 como sendo resultado da passagem do ar através da laringe, enquanto outros médicos atribuíam o som à transição do ar de vias de pequenos calibres para outras de calibres maiores ${ }^{2}$. Experimentos in vitro mostraram que o som vesicular ocorria mesmo se a traquéia fosse retirada e sabe-se hoje que estes sons são gerados na estrutura intralobar e eventualmente intralobular do pulmão².

Em estudos revisados também por Dalmay et al. ${ }^{2}$, encontrou-se a variação de 50 a $1000 \mathrm{~Hz}$ de freqüência e observou-se que: 1) a amplitude do som era maior na inspiração, em contraste com os sons bronquiais; 2) os valores absolutos da amplitude foram mais baixos do que encontrados no som bronquial e seus espectros diferiram ligeiramente; 3 ) os sons vesiculares foram claramente distinguíveis em $100 \mathrm{~Hz}$, mas a amplitude do som saiu da linha de base por volta de 900 a $1.000 \mathrm{~Hz}$, muito mais rápido que os sons bronquiais.

O espectro do som pulmonar se alterou com a idade em todos os focos de ausculta, quando colocados eletrodos nos terceiros e sétimos espaços intercostais direito e esquerdos ${ }^{4}$. A comportamento com a idade foi de mesma magnitude entre os homens e as mulheres sendo a diferença em relação à idade atribuída a mudanças na estrutura tissular, o que implica numa mudança funcional do pulmão 4 . Neste mesmo estudo foi encontrada uma diferença em freqüências mais altas entre homens e mulheres e não foi encontrada diferença significativa entre os fumantes e não fumantes ${ }^{4}$. $O$ índice de massa corpórea (IMC) ajustado para a idade com os sons pulmonares não se alterou ${ }^{4}$. Foram considerados não-fumantes os indivíduos com menos de cinco anos de tabagismo, fossem eles fracionados ou contínuos.

Do ponto de vista prático, não existe nenhuma necessidade em considerar a diferença entre os gêneros, IMC e idades ao proceder a uma ausculta pulmonar 4 .

Os sons pulmonares são motivados pelo fluxo de ar. Se não existe fluxo, não existe som! $!^{2,4}$. Um estudo curioso ${ }^{2}$ submeteu os sujeitos a inspirações com a glote fechada e, ainda assim, foram registradas fracas amplitudes de som. Este registro foi atribuído ao trânsito de ar do ápice a base do pulmão².

\section{Sons pulmonares anormais}

A compreensão dos ruídos pulmonares anormais pelos profissionais da área de saúde é de extrema importância pelo seu íntimo e freqüente contato na prática diária. Com o método barato e seguro da ausculta, pode-se deduzir o que está acontecendo com as estruturas pulmonares e guiar uma abordagem mais proveitosa e funcional com menores riscos ao paciente.

Os acometimentos patológicos do pulmão afetam diretamente a transmissão dos sons pulmonares das vias aéreas à superfície torácica ${ }^{5}$. Pacientes com enfisema pulmonar apresentam sons diminuídos, enquanto nos acometidos pelo edema pulmonar cardiogênico, os sons tornam-se mais audíveis ${ }^{5}$. Nestes dois exemplos podemos imaginar a relação direta entre a patologia, a densidade das estruturas e a geração de sons. Os sons pulmonares anormais, ou ruídos adventícios, podem ser classificados em sibilos, crepitações e roncos ou, também, podem ser classificados pelo seu caráter contínuo e descontínuo.

Os sibilos são ruídos adventícios musicais de diapasão alto parecidos com "assobios", também chamados de contínuos pela sua duração maior 
que $250 \mathrm{~ms}^{5,6}$ e comumente encontrado na fase expiratória. Estudos revisados por Meslier et al. ${ }^{6}$ mostraram variações de 80 a $1.600 \mathrm{~Hz}$, mas segundo a nomenclatura dos sons pulmonares da American Thoracic Society (ATS) este número mostra-se de $400 \mathrm{~Hz}$ para cima.

A formação do sibilo é uma interação entre o calibre da via aérea e a passagem em jato do ar que produz vibrações nas estruturas pulmonares ${ }^{6,7}$. Este som é característico de grandes vias aéreas ${ }^{5,7} \mathrm{e}$ ocorrem quando a velocidade do fluxo de ar alcança um valor crítico que é dependente das características mecânicas e físicas da via aérea e do $a^{6}$. Para as vias aéreas de $5 \mathrm{~mm}$ ou mais de diâmetro os sibilos são de baixa intensidade, enquanto as vias com $2 \mathrm{~mm}$ ou menos são incapazes de transmitir os sons pela dissipação da energia como calor na fricção do ar $^{6}$. Fiz et al. ${ }^{7}$ criou a hipótese de que as últimas gerações capazes de gerar sibilos são os brônquios subsegmentares de 4 a $5 \mathrm{~mm}$ de diâmetro. Em situações clínicas onde isso ocorre, como na asma, a redução da luz da via aérea associada à diminuição de elastância que acompanha o edema, permitem que alguns pacientes possam até apresentar sibilos audíveis à distância 6 . Outras situações que envolvem este sinal clínico são: tumores intraluminais, secreções, corpos estranhos, compressões externas por alguma massa ou compressão dinâmica da via aérea ${ }^{6}$. Caso mais de uma via aérea seja obstruída pode-se encontrar sibilos de diferentes sons, ou polifônicos ${ }^{7}$. Curiosamente, indivíduos sadios podem produzir sibilos quando exercem expirações forçadas ${ }^{6,7}$ e seus mecanismos não são totalmente elucidados ${ }^{5}$.

Em estudos revisados por Meslier et al. ${ }^{6}$ não se revelou unanimidade entre os autores na relação direta do aumento de intensidade dos sons e níveis de broncoespasmo, enquanto Pasterkamp el al. ${ }^{5}$ revelou que a sensibilidade da ausculta dos sibilos na detecção de hipereatividade brônquica foi de 50 a 75\%. Outro parâmetro para suspeitar da broncoconstricção, por exemplo, é a diminuição do som auscultado sem a presença clássica do sibilo ${ }^{5}$. Esta diferença na ausculta ocorre em diminuições do $\mathrm{VEF}_{1}$ (volume expiratório forçado medido no primeiro segundo) abaixo de $10 \%{ }^{5}$. Este som contínuo e musical quando gerada na via aérea superior é chamada de estridor6.

Os roncos são sons contínuos, assim como os sibilos, de diapasão baixo, com freqüência de 200 $\mathrm{Hz}$ ou menos ${ }^{6}$, audíveis na inspiração e na expiração produzido normalmente pelo estreitamento da via aérea com secreção.

Alguns pesquisadores ${ }^{6}$ propuseram o abandono desta nomenclatura e o uso dos termos: sibilos de alto diapasão e de baixo diapasão.

As crepitações, ou estertores são sons descontínuos, apresentada de forma curta e explosiva, usualmente associada com desordens cardiopulmonares ${ }^{8}$. Popularmente são reproduzidas de uma forma didática como o som resultante do roçar de fios de cabelo. São gerados, durante a inspiração, pela abertura súbita de pequenas vias aéreas até então fechadas e, na expiração, pelo fechamento das mesmas ${ }^{8}$. Cada crepitação resulta da abertura e fechamento de uma única via e pode ser motivada pelo aumento na retração, pelo edema e pela inflamação do tecido pulmonar ${ }^{8}$. A forma, o sincronismo, o número e distribuição regional estão associados com a severidade e o caráter da patologia subjacente. Com o processo do envelhecimento e com a perda do recolhimento elástico, as crepitações tendem a aumentar ${ }^{8}$.

As crepitações também foram encontradas em pessoas jovens e sadias quando realizavam uma inspiração profunda a partir do volume residual, mas não da capacidade residual funcional ${ }^{8}$. Este dado nos leva a crer que estes sons não são exclusivos de indivíduos com acometimento patológico e sim, também, dos volumes pulmonares envolvidos durante a ausculta ${ }^{8}$. Os alvéolos basais de um pulmão normal partindo do volume residual insuflam no final de uma inspiração, já no final da expiração as vias aéreas basais são as primeiras a serem fechadas. Por este motivo as crepitações aparecerão mais freqüentemente nas regiões basais nos estágios mais avançados da doença ${ }^{8}$. Estes sons podem diminuir durante várias tomadas de ausculta pulmonar, pelo fato de haver uma maior expansão do pulmão e diminuição de áreas previamente colapsadas ${ }^{8}$.

Laënnec, em seu tratado de ausculta, caracterizou as crepitações em: 1) crepitações úmidas; 2) crepitações mucosas; 3 ) crepitações sonoras secas; e 4) crepitações secas sibilantes ${ }^{8}$. A caracterização destes sons quanto seu caráter seco e úmido, não são mais recomendadas ${ }^{8}$. Não existe uma unanimidade entre os profissionais quanto esta nomenclatura e a classificação mais moderna é baseada no diapasão e na duração dos sons ${ }^{8}$. Os termos crepitações finas, para sons de alta freqüência e pequena duração e crepitações grossas, para sons com freqüência mais baixa e duração mais longa, segundo recomendações da $\mathrm{ATS}^{8}$. As crepitações finas ocorrem normalmente no final da inspiração e não se alteram com a tosse, enquanto as grossas são precoces e se alteram com esta manobra. O tempo durante o ciclo ventilatório onde aparece o som deve ser relatado ${ }^{8}$. Podem aparecer no início, no meio, no final da inspiração, na expiração ou em todo 0 ciclo ${ }^{8}$. Alguns fatores podem limitar a ausculta destes sons como o tipo de estetoscópio, a sensibilidade auditiva e a habilidade do examinador ${ }^{8}$. 
Carvalho VO, Souza GEC. O estetoscópio e os sons pulmonares: uma revisão da literatura.

Tabela 1. Terminologia dos sons adventícios

\begin{tabular}{lll}
\hline Termo sugerido* & Classificação & Termo alternativo \\
\hline Crepitações & Descontínuo & Estertores crepitantes \\
Sibilos & Diapasão alto, contínuo & Estertores sibilantes \\
& & Estertores musicais \\
& & Roncos sibilantes \\
Roncos & Diapasão baixo, contínuo & Estertores sonoros \\
& & Sibilo de diapasão baixo \\
\hline
\end{tabular}

Fonte: Segundo o Ad Hoc Pulmonary Nomenclature Committee da American Thoracic Society e do American College of Chest Physicians.

$\mathrm{Na}$ fibrose pulmonar, as crepitações ocorrem do meio até o final de cada inspiração do paciente, ou em todo o tempo inspiratório ${ }^{8}$. Nos pacientes com asbestose pulmonar, são descritas crepitações finas que ocorrem somente no meio ou no final de cada inspiração ${ }^{8}$. As mesmas possuem relação radiológica e histológica diretas com as áreas acometidas ${ }^{8}$. A duração das crepitações também depende do tempo de exposição ao asbesto ${ }^{8}$. Na bronquiectasia, as crepitações descritas como gosseiras ocorrem somente no início ou no meio da inspiração ${ }^{8}$. Nesta patologia existe uma perda da elasticidade e do componente muscular, de forma que as paredes dos brônquios se colapsam na expiração seguida de uma abertura súbita na inspiração ${ }^{8}$. Nas doenças pulmonares obstrutivas crônicas (DPOC), as crepitações grosseiras ocorrem no início da inspiração e vai ate a metade da mesma ${ }^{8}$. A causa principal deste fenômeno é o fechamento e a abertura seqüencial dos brônquios proximais estreitados devido à perda da sustentação pela tração elástica e inflamação ${ }^{8}$. As crepitações na insuficiência cardíaca, consideradas grossas, são audíveis nas fases inspiratórias e expiratórias ${ }^{8} . \mathrm{Na}$ pneumonia, as crepitações podem variar conforme a fase da doença ${ }^{8}$. Na fase aguda são grosseiros e aparecem no meio da fase inspiratória, durante a recuperação se manifestam mais na fase final da inspiração ${ }^{8}$. O comportamento deste som na fase aguda é motivado pelo edema e infiltração de células inflamatórias, estreitando os brônquos ${ }^{8}$. Na fase de resolução o parênquima pulmonar torna-se mais seco, mudando o aspecto do som ${ }^{8}$.

O atrito pleural é um rangido, ou crepitação produzido pelo atrito de pleuras inflamadas, são localizados, irregulares, descontínuos, mais intensos na inspiração e não se modificam com a tosse ${ }^{11}$. Em condições normais, os folhetos parietal e visceral deslizam-se sem emitir nenhum som, mas nos casos de pleurite, por se recobrir de exsudato, passam a produzir sons ${ }^{11}$. Sua causa principal é a pleurite seca e a instalação do derrame determina seu desaparecimento ${ }^{11}$.
Os sons vocais auscultados podem revelar dados valiosos quanto às mudanças de densidade das estruturas que envolvem o sistema respiratório e uma idéia da extensão da mesma ${ }^{9}$. Os sons produzidos pela voz e ouvidos na parede torácica constituem a ressonância vocal ${ }^{11}$. Em condições normais estes sons não são compreensíveis, não se distinguindo palavra nem sílaba, motivado pelo abafamento gerado no parênquima pulmonar normal ${ }^{11}$. Toda vez que existe consolidação existe aumento da transmissão do som, ou broncofonia ${ }^{11}$. As situações mais comuns são as consolidações do parênquima pulmonar, como na neoplasia e preenchimentos nos espaços interpleurais por líquido, como no derrame pleural ${ }^{9}$. A egofonia é a perda de timbre, ou pronuncia da $v_{0} z^{9}$, comumente caracterizada como uma voz "nasalada" auscultada no limite superior do líquido ${ }^{10}$. Para reconhecimento deste som, pede-se ao paciente para falar o clássico, mas não necessário, "trinta e três" no momento da ausculta. Quando se ouve com nitidez a voz falada, chama-se pectorilóquia fônica e quando o mesmo acontece com a voz cochichada, chama-se pectorilóquia afonica, o que representa uma facilitação à passagem do som. A ATS recomenda que todos os sons sussurrados ou falados sejam classificados como normais, aumentados ou diminuídos.

\section{Técnicas de ausculta}

A ausculta pulmonar é uma técnica barata, segura e, se bem conduzido, tem uma eficiência bem grande no exame físico do paciente no diagnóstico e na análise do efeito da terapia. Apesar de bastante simples, ela exige alguns cuidados por parte dos profissionais de saúde.

O paciente deve estar com a região a ser auscultada totalmente despida. Em hipótese alguma se deve auscultar por cima de roupa. Este erro grosseiro comumente ocorre na prática clínica e permite que artefatos confundam o resultado dos exames. Uma vez despido, deve-se dar preferência à posição sentada e solicitar que o paciente inspire 
mais profundamente que o habitual com a boca, a fim de neutralizar os sons provenientes do nariz, enquanto a expiração deve ser passiva ${ }^{12}$. Caso o paciente não possa sentar-se, deve-se ampará-lo e se ainda assim não for possível, deve-se colocá-lo em decúbito lateral e auscultar um hemitórax por vez. Uma atenção ao tubo do estetoscópio deve ser dada porque se ele atritar com algum objeto pode promover artefatos. A ausculta deve ser realizada em todo o ciclo ventilatório.

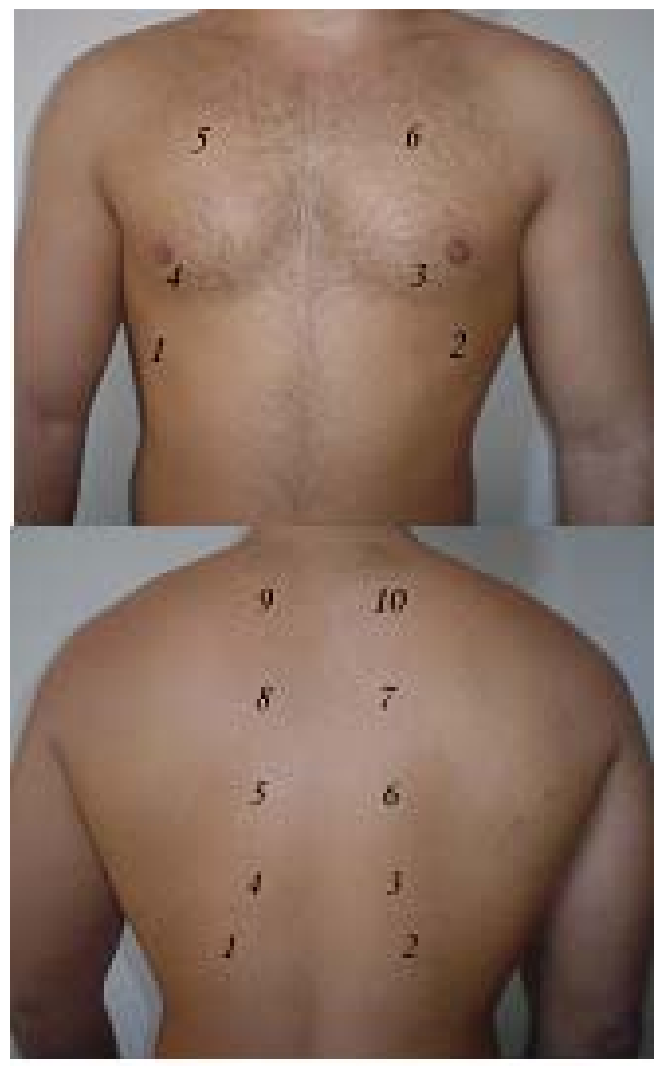

Figura 2. Sítios de ausculta pulmonar

Como contrapartida a todos estes benefícios, o estetoscópio pode ser um potencial vetor de microorganismos e um dos responsáveis pela contaminação de outros pacientes auscultados ${ }^{13}$. Em um total de 300 estetoscópios analisados por Maluf et al. ${ }^{15}, 87 \%$ estavam contaminados e destes $96 \%$ apresentaram mais de um microorganismo ${ }^{13}$. Em outro estudo realizado por Pamar et al. ${ }^{14}$, revelou que $90 \%$ dos 100 estetoscópios analisados estavam contaminados, sendo que $96 \%$ dos usados na pediatria e $100 \%$ dos usados na unidade de terapia intensiva pediátrica estavam contaminados. Recomenda-se o uso do álcool
É importante que o exame seja sistematizado a fim de se auscultar todos os lobos nos respectivos campos pulmonares, simétrica e comparativamente. Orienta-se iniciar pelas bases porque várias tomadas e inspirações poderiam alterar eventuais ruídos adventícios motivados pela reexpansão pulmonar. As Figuras 2, 3 e 4 ilustram os sítios de ausculta pulmonar. Na ausculta das faces laterais do tórax, é interessante solicitar a flexão do ombro para melhor acesso.

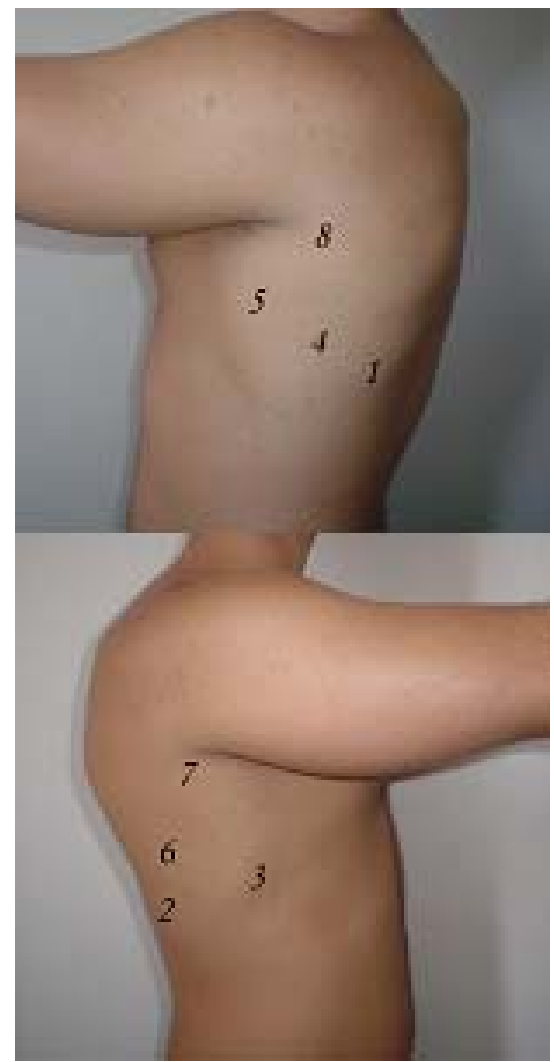

Figura 3 e 4. Sítios de ausculta pulmonar das faces laterais do tórax

a $70 \%$ para limpeza do aparelho ${ }^{13}$ a cada uso.

\section{Curiosidade}

Um estudo realizado por Hanley et al..$^{15}$ analisou duas posições, uma tradicional e outra mais "moderna" que os profissionais de saúde "penduram" o estetoscópio quando não estão usando e comparouas quanto ao tempo necessário para colocá-lo na posição funcional de ausculta. As duas posições estão ilustradas nas Figuras 5 e 6 . O estudo concluiu que a posição moderna foi menos eficiente com uma 
diferença de 1.3 segundos ( $p<0,001$ ) e extrapolou este dado para o número de 197.500 profissionais no Canadá e admitindo que os mesmos usam o estetoscópio 20 vezes ao dia e que o custo por hora em

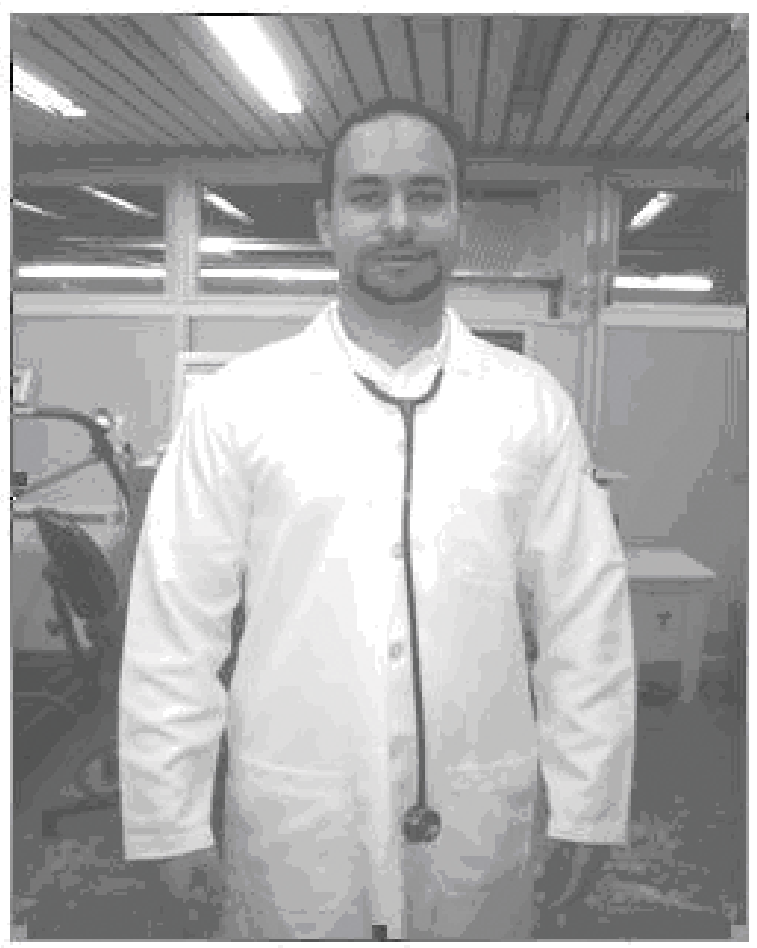

Figura 5. Tradicional

\section{Considerações finais}

Os sons pulmonares são ferramentas diagnósticas muito preciosas pela sua eficiência, praticidade e baixo custo. A ausculta pulmonar quando associada à inspeção, palpação e a percussão bem feitas oferecem ao profissional de saúde informações, muitas das vezes, decisivas no média de um profissional é de 75 dólares ${ }^{15}$. Chegouse ao número de 20.5 milhões de dólares "jogados fora" com o tempo de tirar o aparelho de pescoço e auscultar o paciente ${ }^{15}$.

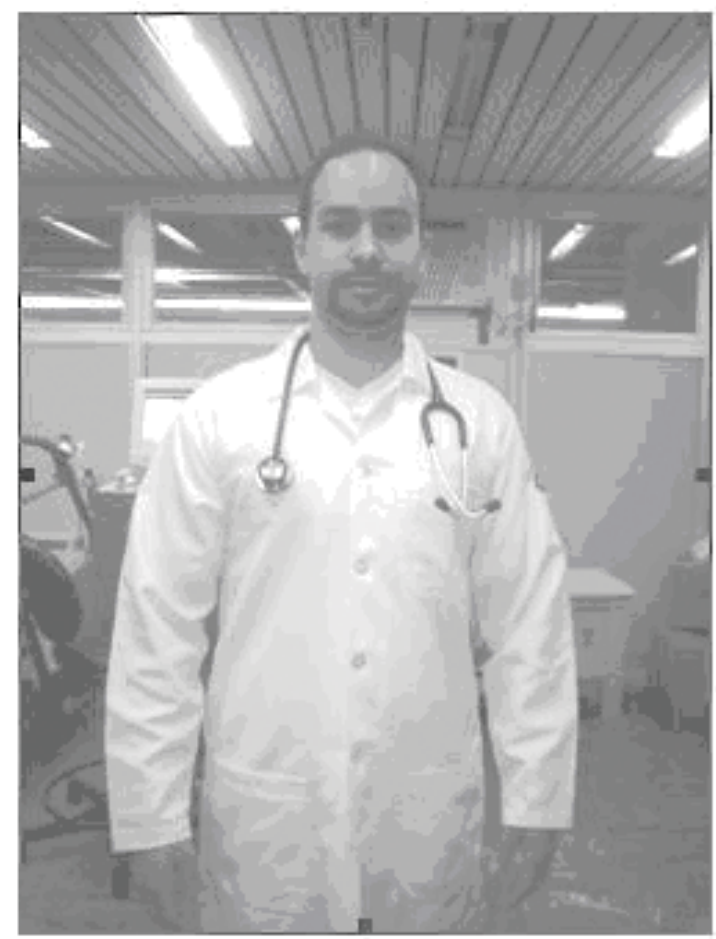

Figura 6. Moderna

diagnóstico e tratamento do paciente.

A evolução tecnológica e dos métodos diagnósticos "enfeitiçam" os profissionais de forma que a propedêutica está, cada vez mais, sendo negligenciada. Este fato reflete em uma maior exposição do paciente a radiações e técnicas invasivas além de um ônus financeiro elevadíssimo no diagnóstico e no monitoramento dos enfermos.

Carvalho VO, Souza GEC. The stethoscope and the pulmonary sounds: a literature review. Rev Med (São Paulo). 2007 out.-dez.;86(4):224-31.

ABSTRACT: The chest auscutation is an old diagnose very widely used in the present time for its low cost, great praticity and sensitivity. The diverse audible pulmonary sounds give health professionals important spots of pulmonary conditions to guide the treatment. These sounds results from lung vibrations and their airways transmited to the chest surface. They can first be divided in: bronchial (traqueobonchial) or vesicular, not existing standardization in its description. The aim of this review is to show what exists about pulmonary sounds and its meanings.

KEY WORDS: Pulmonary sounds, Stethoscopes. Auscutation. Review literature. 


\section{REFERÊNCIAS}

1. Welsby PD, Parry G, Smith D. The stethoscope: some preliminary investigations. Postgrad Med J. 2003;79: 695-8.

2. Dalmay F, Antonini MT, Marquet P, Menier R. Acoustic properties of normal chest. Eur Respir J. 1995;8:1761-9.

3. Tan SY, Yeow ME. René Laennec (1781-1826): inventor of the stethoscope. Singapore Med J. 2005; 46(3):106-7.

4. Gross V, Dittmar A, Penzel T, Schüttler F, Wichert P. The relation between normal lung sounds, age and gender. Am J Respir Crit Care Med. 2000;162:905-9.

5. Pasterkamp H, Kraman SS, Wodicka R. Respiratory sounds, advances beyond the stethoscope. Am J Respir Crit Care Med. 1997;156:974-87.

6. Meslier N, Charbonneau G, Racineux JL. Wheezes. Eur Respir J. 1995;8:1942-8.

7. Fiz JA, Jané R, Homs A, Izquierdo J, García M, Morera J. Detection of weezing during maximal forced exalation in pacients with obstructed airways. Chest 2002;122:186-91.
8. Piirilä P, Sovijärvi ARA. Crackles: recording, analysis and clinical significance. Eur Respir J. 1995;8: 213948.

9. Sapira JD. About egophony. Chest 1995;108:865-7.

10. Silva GA. Derrames pleuras: fisiopatologia e diagnóstico. Medicina (Ribeirão Preto). 1998;31:208-15.

11. Porto CC. Tórax. In: Exame clínico, bases para a prática médica. 5a. ed. Rio de Janeiro: Guanabara Koogan; 2004. p. 272.

12. Scanlan CL, Wilkins RL, Stoller JK; Avaliação do paciente à beira do leito. In: Fundamentos da terapia respiratória de egan. 7a. ed. São Paulo: Manole; 2000. p. 325-30.

13. Maluf MEZ, Maldonado AF, Bercial ME, Pedroso SA. Stethoscope: a friend or an enemy? São Paulo Med J. 2002;120(1):13-5.

14. Parmar RC, Valvi CC, Sira P, Kamat JR. A prospective, randomised, double-blind study of comparative efficacy of immediate versus daily cleaning of stethoscope using $66 \%$ ethyl alcohol. Indian J Med Sci. 2004;58:423-30.

15. Hanley WB, Hanley J G. The efficacy of stethoscope placement when not in use: tradicional versus "cool". JAMC. 2000;163(12):1562-3. 